\title{
Comparison of a low carbohydrate and low fat diet for weight maintenance in overweight or obese adults enrolled in a clinical weight management program
}

\author{
James D LeCheminant*1, Cheryl A Gibson ${ }^{2}$, Debra K Sullivan³, Sandra Hall4, \\ Rik Washburn ${ }^{5}$, Mary C Vernon ${ }^{6}$, Chelsea Curry ${ }^{7}$, Elizabeth Stewart ${ }^{8}$, \\ Eric C Westman ${ }^{9}$ and Joseph E Donnelly ${ }^{5}$
}

Address: ${ }^{1}$ Department of Kinesiology and Health Education, Southern Illinois University Edwardsville, Edwardsville, USA, ${ }^{2}$ General and Geriatric Medicine, University of Kansas Medical Center, Kansas City, USA, ${ }^{3}$ Dietetics and Nutrition, University of Kansas Medical Center, Kansas City, USA, ${ }^{4}$ University of Kansas Medical Center, Kansas City, USA, ${ }^{5}$ Center for Physical Activity and Weight Management, University of Kansas, Lawrence, USA, ${ }^{6}$ Private Bariatric and Family Practice, Lawrence, USA, ${ }^{7}$ Vince \& Associates Clinical Research, Overland Park, USA, ${ }^{8}$ TransforMED, Leawood, KS, USA and ${ }^{~}$ Department of Medicine, Duke University, Durham, USA

Email: James D LeCheminant* - jlechem@siue.edu; Cheryl A Gibson - cgibson@kumc.edu; Debra K Sullivan - dsulliva@kumc.edu; Sandra Hall - sandy_b_h@hotmail.com; Rik Washburn - rwashburn@ku.edu; Mary C Vernon - mvernonmd@yahoo.com; Chelsea Curry - chelsea-curry@hotmail.com; Elizabeth Stewart - estewart@transformed.com; Eric C Westman -westm001@mc.duke.edu; Joseph E Donnelly - jdonnelly@ku.edu

* Corresponding author

Published: I November 2007

Nutrition Journal 2007, 6:36 doi:10.1 186/1475-2891-6-36
Received: 16 January 2007

Accepted: I November 2007

This article is available from: http://www.nutritionj.com/content/6/I/36

(C) 2007 LeCheminant et al; licensee BioMed Central Ltd.

This is an Open Access article distributed under the terms of the Creative Commons Attribution License (http://creativecommons.org/licenses/by/2.0), which permits unrestricted use, distribution, and reproduction in any medium, provided the original work is properly cited.

\begin{abstract}
Background: Recent evidence suggests that a low carbohydrate (LC) diet may be equally or more effective for short-term weight loss than a traditional low fat (LF) diet; however, less is known about how they compare for weight maintenance. The purpose of this study was to compare body weight (BW) for participants in a clinical weight management program, consuming a LC or LF weight maintenance diet for 6 months following weight loss.

Methods: Fifty-five (29 low carbohydrate diet; 26 low fat diet) overweight/obese middle-aged adults completed a 9 month weight management program that included instruction for behavior, physical activity (PA), and nutrition. For 3 months all participants consumed an identical liquid diet (2177 kJ/day) followed by I month of re-feeding with solid foods either low in carbohydrate or low in fat. For the remaining 5 months, participants were prescribed a meal plan low in dietary carbohydrate $(\sim 20 \%)$ or fat $(-30 \%)$. BW and carbohydrate or fat grams were collected at each group meeting. Energy and macronutrient intake were assessed at baseline, 3, 6, and 9 months.

Results: The LC group increased BW from $89.2 \pm 14.4 \mathrm{~kg}$ at 3 months to $89.3 \pm 16.1 \mathrm{~kg}$ at 9 months $(P$ $=0.84)$. The LF group decreased BW from $86.3 \pm 12.0 \mathrm{~kg}$ at 3 months to $86.0 \pm 14.0 \mathrm{~kg}$ at 9 months $(P=$ $0.96)$. BW was not different between groups during weight maintenance $(P=0.87)$. Fifty-five percent $(\mid 6 /$ $29)$ and $50 \%$ (I3/26) of participants for the LC and LF groups, respectively, continued to decrease their body weight during weight maintenance.
\end{abstract}

Conclusion: Following a 3 month liquid diet, the LC and LF diet groups were equally effective for BW maintenance over 6 months; however, there was significant variation in weight change within each group. 


\section{Background}

Multiple treatment strategies are available for weight loss including energy restriction, physical activity, and/or behavioral modification. However, as noted by Wing and Phelan, only $20 \%$ of overweight individuals losing weight are successful for weight maintenance when defined as losing at least $10 \%$ of initial body weight and maintaining the loss for at least 1 year $[1,2]$. Thus, improved strategies to prevent weight re-gain are needed.

Recently, diets lower in carbohydrate and higher in protein have shown promise for weight loss when compared to typical reduced energy and fat diets. In particular, multiple studies indicate that a low carbohydrate diet may produce greater weight loss than a traditional low fat diet over 6 months and may be comparable to a low fat diet over 12 months [3-7]. Despite the evidence supporting a low carbohydrate diet as an effective tool for weight loss its effect for weight maintenance is unclear. Therefore, the purpose of this study was to compare body weight re-gain in overweight and obese adults consuming a low carbohydrate or traditional low fat diet over 6 months of weight maintenance subsequent to 3 months of weight loss.

\section{Methods \\ Participants}

This study was approved by the Human Subjects Committee at the University of Kansas and participants provided informed consent prior to participation in the study. Participants were recruited through advertisements, fliers, and word of mouth. Participants were healthy adults, 19 to 70 years of age, previously sedentary, and overweight or obese $\left(\mathrm{BMI}>27 \mathrm{~kg} / \mathrm{m}^{2}\right)$. Individuals were excluded if they smoked, used special diets (i.e. vegetarian), were unable to exercise (i.e. walk), were pregnant or lactating, or were in active counseling for any psychological or psychiatric condition. Prior to participation, a physician evaluated each individual to determine potential health risks relative to participation in the study. Individuals were excluded for any metabolic disease affecting energy balance (e.g. diabetes mellitus, cancer, etc.). Except for the exclusion criteria stated above, there were no restrictions for gender, race, or socioeconomic status.

\section{Study design}

This study was conducted in the context of a weight management clinic. All participants received 3 months of a weight loss diet followed by 6 months of a weight maintenance diet either low in carbohydrate or fat. A quaziexperimental design was utilized where clinic site was assigned as either low carbohydrate or low fat; however, analysis was per participant. A total of six separate cohorts ( 15-20 participants each) were recruited; 3 low carbohydrate and 3 low fat. Cohorts within each dietary intervention did not differ by protocol, format, or instruction.

\section{Weight management clinics}

Weight management clinic meetings were approximately 90 min and were held weekly for the first 6 months and biweekly for the subsequent 3 months. Clinics were conducted in a group format of 15-20 individuals and each meeting began with a check-in to ensure adherence to the protocol of the study. During check-in, all participants were weighed and provided their self-reported weekly data including: \# of liquid shakes consumed (weight loss period only), total g of carbohydrate or fat (weight maintenance period only), min of physical activity (PA), and number of steps recorded by step counters. Following check-in, a 30-45 min presentation was given including instruction in behavioral lifestyle modification, exercise, or nutrition.

In order to increase accountability and protocol compliance participants were asked to provide a mid-week checkin via phone, fax, or email during the first 6 months of the study. For the mid-week check-in participants provided their weekly data (PA, steps, etc.) and presented any concerns related to the study they might have had since the previous meeting. When group meetings changed to biweekly, check-ins occurred during the week groups did not meet. All group meetings were lead by the same staff of registered dieticians, exercise physiologists, and behavioral therapists using an identical, standardized protocol.

The only difference in group meetings occurred when the meeting topic was nutrition. All participants consuming a low carbohydrate diet received information and strategies for achieving a diet low in carbohydrate such as shopping, cooking, label reading, etc., and the participants consuming a low fat diet received information and strategies for eating a diet low in fat. Attendance was expected at group meetings. Prior to participation in the study, participants agreed to comply with a $75 \%$ attendance rate requirement and understood that they would be terminated from further participation in group meetings if their attendance fell below $75 \%$.

\section{Very low-energy diet}

Weight loss was facilitated using a very low-energy diet (VLED) comprised of $2177 \mathrm{~kJ} /$ day for 3 months. During VLED, we utilized a milk-based product (Health Management Resources, Boston, MA) consumed primarily as a liquid shake at 5 intervals throughout the day. Each liquid shake included approximately $435 \mathrm{~kJ}, 13-17 \mathrm{~g}$ of carbohydrate, $1 \mathrm{~g}$ of fat, $10-14 \mathrm{~g}$ of protein. In addition, a vitamin and mineral supplement was taken twice daily. If participants did not lose at least $10 \%$ of their initial body weight during VLED, they were not allowed to continue with the study. The liquid meal replacements were the only source of nutrition during VLED with the exception of noncaloric beverages that were consumed ad libitum. To 
ensure compliance to the VLED, participants reported their total number of liquid shakes consumed for the previous week at each group meeting.

\section{Weight maintenance diet}

During month 4, a progressive re-feeding schedule was utilized that decreased the number of liquid shakes and increased the number of solid foods consumed each week. This was done to limit adverse events (e.g., nausea, diarrhea, etc.) associated with the transition from the liquid to the solid food diet. Further, the low carbohydrate group was re-fed with solid foods that were low in carbohydrate, such as green leafy vegetables, broccoli florets, lean meats, and nuts and the low fat group was re-fed with low fat foods, such as fruits, vegetables, potatoes, and whole grains.

At the end of month 4, all participants were provided a gram level of carbohydrate or fat based upon their weight maintenance energy requirements. For the low carbohydrate group, the upper limit of carbohydrate grams to be consumed each day was $\sim 20 \%$ of their total maintenance energy level and for the low fat group the upper limit of fat grams to be consumed each day was $\sim 30 \%$ of their total maintenance energy level. Maintenance energy intakes were calculated using the Harris-Benedict equation to estimate resting energy expenditure (REE) and we used $1.4 \times$ REE to adjust for PA levels [8].

To monitor adherence to the diet, the low carbohydrate group kept a daily tally of grams of carbohydrate consumed and the low fat group kept a daily tally of the number of fat grams consumed, based upon the percentages previously listed, and reported their daily gram total at each weekly meeting. To increase the likelihood that participants would eat according to their diet, group meetings emphasized food label reading, low carbohydrate or low fat food preparation, low carbohydrate or low fat food items and low carbohydrate or low fat food recipes, etc. If participants tended to exceed their allotted number of daily carbohydrate or fat grams, a member of the research staff provided dietary counseling to the particular participant.

\section{Body weight and regional adiposity}

Weights were obtained at the beginning of each group meeting using a digital scale (Befour, Inc., Saukville, WI) accurate to $\pm 0.1 \mathrm{~kg}$ with participants wearing normal clothing without shoes. To calculate BMI, height was measured at baseline using a stadiometer (Perspective Enterprises, Portage, MI). Body Mass Index was calculated as weight in $\mathrm{kg}$ divided by height in meters squared $(\mathrm{kg} /$ $\mathrm{m}^{2}$ ). Waist circumference was measured at the narrowest portion of the abdomen and hip circumference was measured at the widest portion of the buttocks [9]. Waist and hip circumference were assessed at baseline, 3, 6, and 9 months by obtaining 2 measurements per site within $2 \mathrm{~cm}$ using a spring-loaded tape measure (Creative Health Products, Ann Arbor, MI).

\section{Energy intake}

In order to determine compliance to the diet, 3-day food records were analyzed at baseline, 3, 6, and 9 months. For 3 separate days in a week, including 2 weekdays and 1 weekend day considered typical, each participant recorded all foods and beverages consumed; both type and amount. During group meetings, participants were trained to read food labels and estimate portion sizes in order for amounts to be determined. Upon collection, a trained staff member reviewed each participant's diet record for accuracy and gave suggestions to better comply with the diet if needed. At each data collection period, diet records were entered into the Nutrition Data System for Research (NDSR) (version 4.05_33) by a trained staff member for nutrient composition and energy intake analysis.

\section{Physical activity}

Physical activity (PA) was considered any planned activity of at least moderate-intensity, such as brisk walking, involving major muscle groups that lasted for $10 \mathrm{~min}$ or more. Participants were issued pedometers (Accusplit ${ }^{\circledR}$, San Jose, CA) and instructed in their use. Weekly totals for PA in min and steps were reported at each group meeting. Physical activity was initiated after the second clinic meeting and was progressive beginning with 15 min per day, three times/week and reached 50-60 min, 5-6 times/ week at month 6 . The overall goal was for participants to reach a PA level of $300 \mathrm{~min} /$ week at 6 months and maintain that level for the remainder of the study. The progression was intentionally slow to decrease the likelihood of injury as many participants were unaccustomed to regular physical activity.

\section{Blood pressure}

Blood pressure was assessed at baseline, 3, 6, and 9 months. Blood measure was measured on the right arm using a mercury sphygmomanometer with participants lying in the supine position for $5 \mathrm{~min}$ prior to measurement [10]. A minimum of two blood pressure measurements were taken. If the first two readings differed by more than $5 \mathrm{mmHg}$, an additional reading was obtained. The lowest systolic and diastolic blood pressure values were used for analysis [11].

\section{Adverse events}

At each clinic meeting, participants reported any adverse events experienced during the previous week. A form was provided to assess potential adverse events that included questions about nausea, fatigue, flatulence, bad breath, 
constipation, bloating, stomach cramps, diarrhea, hair loss, change in sleeping patterns, over the counter drugs, insomnia, irritability, body odor, etc. The form containing the list of potential adverse events also included a space to allow participants to explain the adverse event or to describe an event not listed on the form (i.e. "other").

\section{Statistical analysis}

The statistical software package PC-SAS (version 8.2, SAS Institute, Inc., Cary, NC) was employed for all statistical analyses. The level of significance was set at 0.05 for all statistical tests. Descriptive statistics (mean, standard deviation, etc.) were reported for all dependent measures such as body weight, energy and macronutrient intake, etc. The primary outcome was a comparison of body weight during weight maintenance ( 4 months to 9 months) for the two treatment conditions. For differences in body weight between groups, we applied intention to treat principles by including participants in the analysis who had withdrawn from the study. However, as this was a per protocol study and as there was no difference in statistics when analyzing using intention to treat analysis or per protocol, data and statistics presented hereafter will be reported exclusively for participants who completed the entire duration of the study and all laboratory assessments. Ttests and repeated measures ANOVA were used to detect differences in the change in body weight over time. In addition, mixed effects models were used in order to assess if there was a significant interaction (group*time) for each dependent variable. An autoregressive [AR(1)] covariance structure was assumed for the mixed effects models. In the absence of a significant interaction term, analysis was completed for the main effects of group and time.

\section{Results}

\section{Participants}

A total of 102 participants met the inclusion criteria and initiated the study. The participants were healthy adults (26 men and 76 women), middle-aged, and obese. Ninety-four percent (96/102) of participants were Caucasian, 3\% (3/102) were African-American, and 3\% (3/102) were Hispanic. Twenty percent (20/102) of participants reported using medications including: anti-hypertensives, diuretics, thyroid medications, or anti-depressants. At baseline, 52 participants were assigned to the low carbohydrate diet group and 50 participants were assigned to the low fat diet group. There were no statistical differences between the low carbohydrate and low fat group at baseline for age, weight, or BMI.

\section{Attrition and adherence}

The low carbohydrate group had $44 \%$ attrition and the low fat group had $48 \%$ attrition. A summary of reasons for participant attrition and the number of dropouts are included in Table 1. Attrition was greatest during months 4 to 6 for both groups. A total of 55 participants (29 low carbohydrate; 26 low fat) completed all testing and clinic measures at 9 months. There was no statistical difference at baseline for body weight between those who completed the study and those that did not $(P=0.14)$. Characteristics of completers at baseline are presented in Table 2 .

During the weight loss portion of the study, participants achieved the required number of liquid meal replacements averaging $35 \pm 3$ per week for the low carbohydrate group and $36 \pm 4$ per week for the low fat group. Throughout the duration of weight maintenance (months 4-9) participants kept track of daily carbohydrate or fat grams with the low carbohydrate group self-reporting a consumption of $78 \pm 30 \mathrm{~g}$ of carbohydrate per day and the low fat group self-reporting $39 \pm 18 \mathrm{~g}$ of fat per day. In addition, analysis of 3-day food records showed the low carbohydrate group consumed an average of $91 \pm 39 \mathrm{~g}$ of carbohydrate per day equaling $\sim 25 \%$ of total $\mathrm{kJ}$ from carbohydrate and the low fat group consumed an average of $48 \pm 20 \mathrm{~g}$ of fat per day averaging $\sim 26 \%$ of total $\mathrm{kJ}$ from fat, throughout the duration of weight maintenance.

\section{Pre-study diet}

Prior to participation (baseline), energy intake was higher in the low fat group compared with the low carbohydrate group $(9439 \pm 2428 \mathrm{~kJ}$ vs. $7761 \pm 1980 \mathrm{~kJ} ; P=0.01)$. In addition, the low fat group consumed a significantly greater number of grams of carbohydrate, fat, and alcohol $(P<0.05)$; however, the percentage of total energy from

Table I: Reasons for withdrawal from the study at each 3 month interval for the low carbohydrate and low fat groups.

\begin{tabular}{|c|c|c|c|c|}
\hline & $\begin{array}{c}\text { Base to } 3 \\
\text { months }\end{array}$ & $\begin{array}{c}3 \text { to } 6 \\
\text { months }\end{array}$ & $\begin{array}{c}6 \text { to } 9 \\
\text { months }\end{array}$ & Total \\
\hline Lack of Attendance & $0 / 0$ & $2 / 6$ & $7 / 1$ & $9 / 7$ \\
\hline $\begin{array}{l}\text { Disliked the Dietary } \\
\text { Protocol During } \\
\text { Maintenance }\end{array}$ & NA & $3 / 0$ & $1 / 1$ & $4 / 1$ \\
\hline $\begin{array}{l}\text { Unable to Comply } \\
\text { with a Liquid VLED } \\
\text { During Weight Loss }\end{array}$ & $4 / 3$ & NA & NA & $4 / 3$ \\
\hline Injury & $0 / 0$ & $2 / 0$ & $0 / 0$ & $2 / 0$ \\
\hline $\begin{array}{l}\text { Disliked Record } \\
\text { Keeping or Other } \\
\text { Components of the } \\
\text { Program }\end{array}$ & $0 / 0$ & $1 / 4$ & $0 / 2$ & $1 / 6$ \\
\hline Monetary Conflict & $0 / 0$ & $1 / 0$ & $0 / 1$ & $1 / I$ \\
\hline Pregnant & $0 / 0$ & $1 / 0$ & $0 / 0$ & $1 / 0$ \\
\hline Work Conflicts & $0 / 0$ & $1 / 2$ & $0 / 1$ & $1 / 3$ \\
\hline Family Conflict & $0 / 0$ & $0 / 0$ & $0 / 2$ & $0 / 2$ \\
\hline Moved from Area & $0 / 0$ & $0 / 1$ & $0 / 0$ & $0 / 1$ \\
\hline Total Dropouts & $4 / 3$ & $11 / 13$ & $8 / 8$ & $23 / 24$ \\
\hline
\end{tabular}

Low carbohydrate/low fat 
Table 2: Baseline characteristics of completers by group.

\begin{tabular}{lccc}
\hline & LC & LF & $P$ \\
\hline N & 29 & 26 & \\
Weight (kg) & $109.6 \pm 17.3$ & $105.5 \pm 15.9$ & 0.36 \\
BMI (kg/m $)$ & $39.1 \pm 5.0$ & $37.6 \pm 4.9$ & 0.27 \\
Waist (cm) & $110.5 \pm 12.7$ & $106.6 \pm 9.6$ & 0.21 \\
Age (y) & $47.9 \pm 10.1$ & $45.7 \pm 10.6$ & 0.28 \\
\hline
\end{tabular}

Mean \pm SD. LC $=$ Low carbohydrate group. LF = Low fat group.

carbohydrate, protein, and fat was not significantly different between dietary groups $(P>0.05)$ (Table 3$)$.

\section{Weight loss period}

During the weight loss period (months 1-3) both groups lost significant amounts of body weight on the VLED. The low carbohydrate group decreased body weight by $20.4 \pm$ $6.2 \mathrm{~kg}(19 \%)$ and the low fat group $19.1 \pm 5.4 \mathrm{~kg}(18 \%)$; the difference between groups was not statistically significant. Likewise, BMI, waist circumference, and blood pressure decreased significantly for both groups but differences between groups were not significant.

\section{Weight maintenance period}

Differences in body weight between the two groups were not significant across the 6 months of weight maintenance $(P=0.87)$. Adjusting for medication use and body weight at the beginning of weight maintenance did not influence the outcome. Figure 1 shows body weight at 2 week intervals across the 6 months of weight maintenance. At the beginning of weight maintenance the low carbohydrate group had a body weight of $89.2 \pm 14.4 \mathrm{~kg}$ that increased to $89.3 \pm 16.1 \mathrm{~kg}$ at 9 months $(P=0.84)$ and the low fat group had a body weight of $86.3 \pm 12.0 \mathrm{~kg}$ at 3 months that decreased to $86.0 \pm 14.0 \mathrm{~kg}$ at 9 months $(P=0.96)$. In the low carbohydrate group, 55\% (16/29) of participants decreased their body weight during weight maintenance and 50\% (13/26) of participants in the low fat group decreased their body weight during weight maintenance (Figures $2 \& 3$ ).

Participants in both treatment groups showed a similar response for blood pressure and anthropometrics during the weight maintenance period. At the beginning of weight maintenance, systolic and diastolic blood pressure were not significantly different between groups although systolic blood pressure was slightly higher in the low carbohydrate group (122 vs. $116 \mathrm{mmHg}$; = 0.08). Over the duration of weight maintenance the low carbohydrate group showed a decrease in systolic blood pressure from $122 \pm 11$ to $120 \pm 10 \mathrm{mmHg}$ and diastolic blood pressure from $75 \pm 7$ to $73 \pm 10 \mathrm{mmHg}$. The low fat group decreased systolic blood pressure from $116 \pm 13$ to $111 \pm$ $13 \mathrm{mmHg}$ and diastolic blood pressure from $73 \pm 8$ to 70 $\pm 9 \mathrm{mmHg}$. There were no significant differences in blood pressure between or within groups across the duration of weight maintenance. Likewise, waist circumference and BMI were not statistically different between or within groups at any time period (Table 4 ).

Comparison of energy and macronutrient intake data during weight maintenance showed that the low carbohydrate group consumed significantly more grams of protein, fat, and percentage of total energy intake from protein and fat compared to the low fat group. The low fat group consumed significantly more total energy, grams of carbohydrate, fiber, and alcohol and a greater percentage

Table 3: Between group comparisons for macronutrient intake at baseline and across weight maintenance.

\begin{tabular}{|c|c|c|c|c|}
\hline & \multirow[b]{2}{*}{ Baseline } & \multicolumn{3}{|c|}{ Weight Maintenance } \\
\hline & & 4-Months & 6-Months & 9-Months \\
\hline \multicolumn{5}{|l|}{ LC Group $(n=29)$} \\
\hline Energy Intake (kJ) & $7761 \pm 1980 *$ & $5180 \pm 1630$ & $6318 \pm 1819$ & $6259 \pm|61| * *$ \\
\hline Carbs (g) & $193 \pm 52 *$ & $75 \pm 26$ & $98 \pm 48$ & $100 \pm 36^{* *}$ \\
\hline Protein (g) & $85 \pm 28$ & $88 \pm 29$ & $99 \pm 37$ & $92 \pm 24^{* *}$ \\
\hline Fat (g) & $83 \pm 29 *$ & $67 \pm 59$ & $81 \pm 28$ & $82 \pm 34 * *$ \\
\hline Alcohol (g) & $3 \pm 6^{*}$ & $2 \pm 4$ & $3 \pm 7$ & $2 \pm 7 * *$ \\
\hline Dietary Fiber (g) & $16 \pm 5$ & $13 \pm 6$ & $14 \pm 6$ & $14 \pm 6^{* *}$ \\
\hline \multicolumn{5}{|l|}{ LF Group $(n=26)$} \\
\hline Energy Intake (kJ) & $9439 \pm 2428$ & $6565 \pm 1623$ & $6996 \pm 2193$ & $7167 \pm 2058$ \\
\hline Carbs (g) & $230 \pm 80$ & $215 \pm 61$ & $215 \pm 72$ & $235 \pm 69$ \\
\hline Protein (g) & $90 \pm 22$ & $83 \pm 23$ & $85 \pm 25$ & $83 \pm 21$ \\
\hline Fat (g) & $103 \pm 32$ & $44 \pm 18$ & $50 \pm 22$ & $49 \pm 21$ \\
\hline Alcohol (g) & $11 \pm 15$ & $6 \pm 13$ & $11 \pm 19$ & $8 \pm 16$ \\
\hline Dietary Fiber (g) & $15 \pm 5$ & $25 \pm 8$ & $26 \pm 13$ & $25 \pm 8$ \\
\hline
\end{tabular}

LC = Low Carbohydrate Group; LF = Low Fat Group. Mean \pm SD. Significance set at $(P<0.05)$.

*Indicates a significant difference from the low fat group at baseline.

**Indicates a significant difference from the low fat group across weight maintenance. 


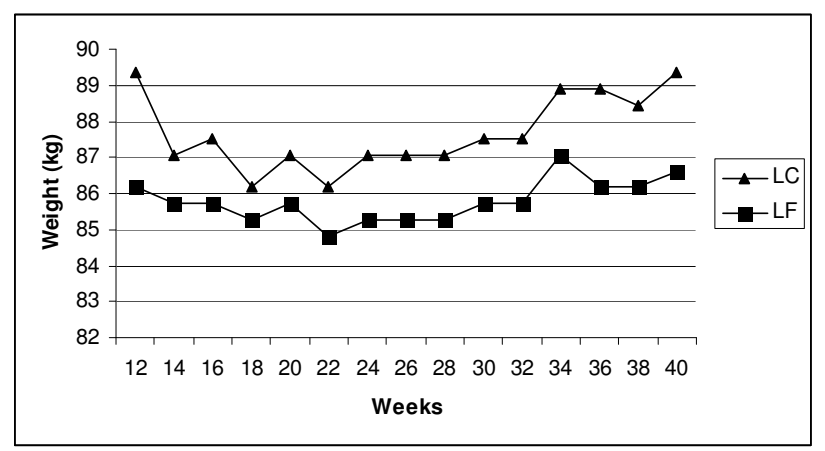

Figure I

Body weight across weight maintenance for low carbohydrate and low fat groups. LC = low carbohydrate group. LF = low fat group. No significant group*time interaction or within group differences $(P>0.05)$.

of total energy intake from carbohydrate and alcohol compared to the low carbohydrate group. After adjusting for baseline, total energy intake and protein intake were no longer significantly different between groups during weight maintenance (Table 3).

\section{Physical activity}

There was not a significant group*time interaction for min of physical activity during weight maintenance. Physical activity for the low carbohydrate group averaged 268 $\pm 17 \mathrm{~min} /$ week and for the low fat group was $265 \pm 23$ min/week during weight maintenance. Likewise, there was not a significant group*time interaction for pedometer steps during weight maintenance. The low carbohydrate group averaged approximately 63,000 \pm 3200 steps per week and the low fat group $68,000 \pm 3500$ steps per week during weight maintenance.

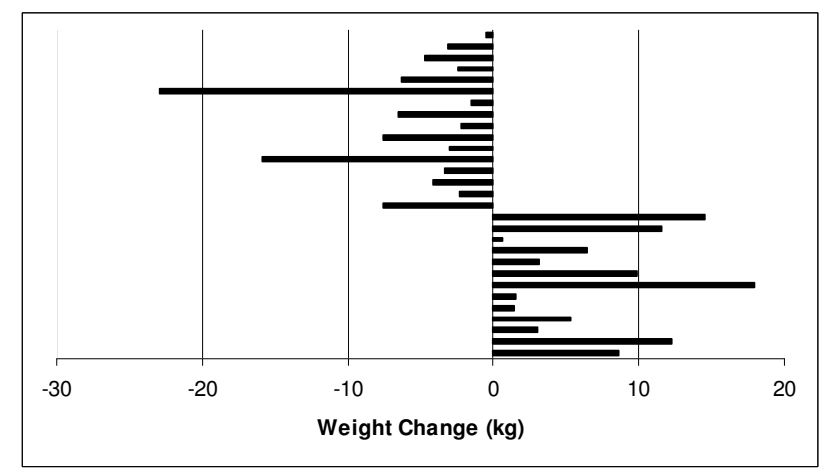

\section{Figure 2}

Individual Participant Responses in Body Weight for the Low Carbohydrate Group during Weight Maintenance.

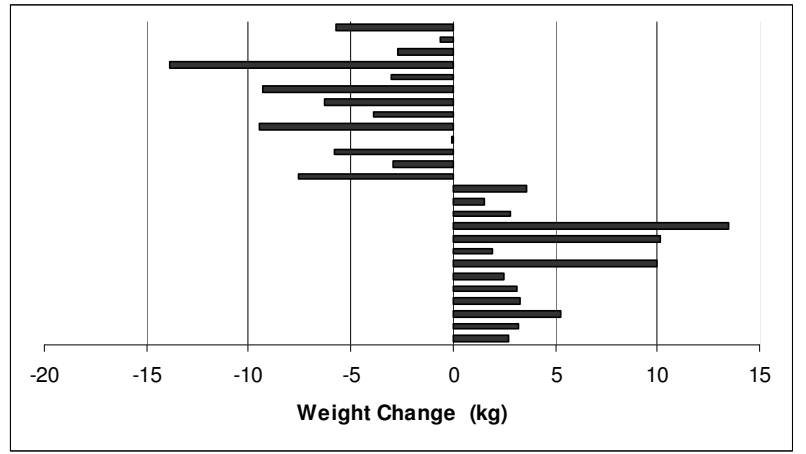

Figure 3

Individual Participant Responses in Body Weight for the Low Fat Group during Weight Maintenance.

\section{Adverse events}

The most commonly reported adverse events in the low carbohydrate group during weight maintenance included headache, constipation, flatus, hair loss, change in sleeping patterns, and stomach cramps. The most commonly reported adverse events in the low fat group during weight maintenance included headache, nausea, fatigue, and diarrhea.

Unexpected adverse events reported in the low carbohydrate diet included dizziness $(\mathrm{N}=2)$, leg cramps $(\mathrm{N}=2)$, a missed menstrual period $(\mathrm{N}=1)$, dandruff $(\mathrm{N}=1)$, decreased sex drive $(\mathrm{N}=1)$, and a $100 \mathrm{mg} / \mathrm{dL}$ increase in total cholesterol in 1 participant. Unexpected adverse events reported in low fat diet included change in taste $(\mathrm{N}$ $=1)$ and dizziness $(\mathrm{N}=1)$.

\section{Discussion}

Prevention of weight re-gain is difficult for many individuals [12-14]. The main finding of this investigation was that subsequent to substantial weight loss on a VLED, a low carbohydrate diet and a low fat diet, combined with a clinical weight management program, were similar and effective to prevent weight re-gain over 6 months. For the low carbohydrate group, body weight remained approximately $19 \%$ below baseline body weight and the low fat group remained approximately $18 \%$ below baseline body weight.

Although both diets were similar to prevent weight regain, not all participants responded uniformly to either intervention. It was not surprising that some participants from both dietary groups regained weight after VLED as this has been reported elsewhere [15]. Further, it is wellknown that not all individuals that lose weight are successful for weight maintenance $[1,2,16]$. However, both dietary groups showed similar variation in weight change 
Table 4: Body weight, BMI, and waist circumference for the low carbohydrate and low fat groups during weight maintenance.

\begin{tabular}{lcccccc}
\hline & \multicolumn{2}{c}{ 3-Months } & \multicolumn{2}{c}{ 6-Months } & & 9-Months \\
& LC & LF & LC & LF & LC & LF \\
\hline N & 29 & 26 & 29 & 26 & 29 & 26 \\
Body Weight (kg) & $89.2 \pm 14.4$ & $86.3 \pm 11.9$ & $87.1 \pm 15.0$ & $85.3 \pm 13.2$ & $89.3 \pm 16.1$ & $86.0 \pm 14.0$ \\
BMI (kg/m $\left.{ }^{2}\right)$ & $31.8 \pm 4.5$ & $30.9 \pm 4.2$ & $31.1 \pm 4.8$ & $30.5 \pm 4.5$ & $31.9 \pm 5.3$ & $30.8 \pm 5.2$ \\
Waist (cm) & $95.9 \pm 10.7$ & $91.4 \pm 8.7$ & $94.9 \pm 14.5$ & $91.4 \pm 10.3$ & $96.3 \pm 12.7$ & $93.4 \pm 10.5$ \\
\hline
\end{tabular}

Mean \pm SD. LC = low carbohydrate group. LF = low fat group. No significant interactions, no differences at 3 months, or within/between groups differences across the duration of the study $(P>0.05)$.

during the weight maintenance period. Fifty-five percent of participants in the low carbohydrate and $50 \%$ of participants in the low fat group continued to decrease their body weight during weight maintenance while the remainder re-gained a portion of their body weight (Figures $2 \& 3$ ).

To attempt to explain the variability in weight change within each group, we examined energy and macronutrient intake differences between weight gainers and losers and found they were generally not significant; however, a couple of trends are interesting. For the low carbohydrate group, there was no difference in energy intake between the weight gainers and losers but the weight losers averaged $13 \mathrm{~g}$ of carbohydrate/day less than the weight gainers $(P=0.16)$. For the low fat group, weight losers consumed $178 \mathrm{~kJ} /$ day less $(P=0.09)$ and $7 \mathrm{~g}$ of fat/day less $(P=0.12)$ than the weight gainers. These trends imply that the level of carbohydrate or fat restriction for each dietary group may be important for subsequent weight change. Accordingly, the carbohydrate or fat level consumed by the weight gainers may not have been sufficient to maintain energy balance or produce an energy deficit. This is especially likely for the low carbohydrate gainers as the average consumption of carbohydrates was higher than reported in other studies $[3,4,6,7]$.

One statistically significant difference between the low carbohydrate weight gainers and losers is noteworthy. The low carbohydrate weight losers consumed an average of 15 grams of protein/day more than the low carbohydrate weight gainers $(P=0.02)$. This is consistent with human and rodent studies that report that increasing protein intake may be beneficial for weight loss and prevention of weight re-gain $[17,18]$. For instance, Westerterp-Plantenga et al reported that additional protein intake (18\% vs. $15 \%)$ resulted in less weight re-gain after 4 weeks of weight loss on a VLED[17]. In addition, increasing the ratio of protein to carbohydrate, as reported by Layman et al, may also be important for continued weight loss and maintenance [19]. Thus, we cannot rule out the possibility that the increased protein intake for the low carbohy- drate group weight losers contributed to their continued decrease in body weight. Regardless of the reason for the variability in weight change within each dietary group, it is likely that both diets, if appropriately applied and adhered to, will yield a measure of success for weight maintenance in some individuals. Perhaps one of the most interesting questions arising from this study for future investigations is "how to determine or predict which individuals are most likely to succeed consuming a specific diet".

For the present study, attrition was similar for both groups. The primary reason for attrition during weight maintenance for both groups was lack of attendance at group meetings. Participants would not always provide reasons for their unwillingness to continue attendance or they intentionally discontinued correspondence and were removed from the study after dropping below the required attendance level (75\%). As a result, we are left to conjecture as to why some participants discontinued attendance. We recognize that the high attrition in both groups is unfortunate and represents a weakness of the study. However, other similar studies have reported high rates of attrition up to $38 \%$ for low carbohydrate groups and $46 \%$ for low fat groups $[4,6,7]$. In a recent meta-analysis of 5 low carbohydrate vs. low fat trials reported by Nordmann et al, attrition rates were $30 \%$ and $43 \%$ for a low carbohydrate and low fat diet, respectively, after 6 months and $38 \%$ and $46 \%$, respectively, after 12 months [20]. As mentioned earlier, in attempt to limit attrition bias, we included an intent to treat analysis which did not change the statistical significance for any variable.

Physical activity is an important component of successful weight maintenance $[21,22]$. Interventions that promote lifestyle changes along with PA have shown better weight maintenance than interventions that do not have these components [21]. For the present study, PA was an important component and was similar for both groups. Both groups were prescribed an identical amount of PA and there was little variation. As a result, any difference in 
body weight change between groups during weight maintenance is not likely due to differences in PA.

Some participants were on prescription medications during the study. However, medication use was generally stable and statistical adjustment for medication use did not significantly influence body weight outcomes. As a result, we do not believe that medication use was a confounding factor. Further, the results are likely to generalize fairly well to an overweight or obese adult population, who are typically taking 1 or more medications such as blood pressure, depression, and lipids [23].

There were more total adverse events in the low carbohydrate group than in the low fat group. However, it should be noted that when adverse events were considered excluding the re-feeding period (month 4) the total number of adverse events reported were essentially the same for both groups. It is possible that the transition from a liquid VLED to solid food is more difficult when consuming a low carbohydrate diet or that our method of re-feeding can be improved to smooth this transition. Commonly reported adverse events for the low carbohydrate group were consistent with other studies, specifically, constipation, and diarrhea $[7,24]$. One participant in the low carbohydrate group had an unexplainable increase in total cholesterol after 3 months on the low carbohydrate diet (total cholesterol increased from 136 to $306 \mathrm{mg} / \mathrm{dL}$ ). This participant was advised to seek medical attention immediately.

We recognize that there are several limitations with this study. 1) The diet and PA data were self-reported. There are known biases and limitations with self-reported data, such as under-reporting energy intake [25]. Nevertheless, diet records are commonly used and acceptable research instruments. 2) There were considerably more women than men and so results were not reported by gender. 3) We chose to use a quazi-experimental design with the site being assigned as either low carbohydrate of low fat rather than to randomize individual participants to a particular group. This was done because the popularity of the Atkins diet was at its height during our data collection. We felt that if participants assigned to different dietary protocols were in the same group or location there would be increased likelihood of data contamination by participants choosing to follow the dietary protocol of their choice rather than their assignment. Further, we did not use a cluster design and analyzed the data by individual participants. Had we analyzed the data by clinic assignment, the sample size would have been $n=2$, insufficient for a cluster, and would likely have biased the results. Nevertheless, we recognize that the study design can be improved for future studies by randomization of participants or randomization by clinic using a cluster design of sufficient sample size. 5) The data collected for adverse events may be biased due to the assessment method. Adverse event data was collected from participants by administering a single sided page that listed specific adverse events seen in other low carbohydrate and low fat studies. We may have inadvertently prompted the participants to consider a specific adverse event they would not necessarily have reported had it not been listed.

\section{Conclusion}

This study addressed a significant gap in the current literature by comparing body weight in participants on either a low carbohydrate diet or low fat diet during a 6 month weight maintenance period following weight loss. The primary finding of this study was that a low carbohydrate and low fat diet, combined with a clinical weight management program, are comparable for body weight maintenance over 6 months; however, there was significant variation in weight change within each group.

\author{
Abbreviations \\ BW $=$ Body Weight (Abstract Only) \\ PA = Physical Activity \\ $\mathrm{g}=$ grams \\ $\min =$ minutes \\ $\mathrm{kJ}=$ kilojoules \\ $\mathrm{kg}=$ kilograms \\ $\mathrm{BMI}=$ body mass index \\ VLED = very low-energy diet \\ REE $=$ resting energy expenditure \\ $\mathrm{cm}=$ centimeters
}

\section{Competing interests}

Dr. Mary C. Vernon receives honoraria as a consultant for Mrs. Veronica Atkins, Chairperson of the Board of Directors for the Robert C. Atkins Foundation. The Atkins Foundation provided partial support for this project. The remaining authors declare that they have no competing interests.

\section{Authors' contributions}

All authors approved the final manuscript. JD conceived the study design with input from JL, RW, DS, CG, SH, MV, and EW. JL, CC, and ES coordinated and executed all aspects of the study with input from RW, DS, CG, and SH. $\mathrm{MV}$ provided medical oversight of all subjects. Data were 
analyzed by JL with support by SH. The manuscript was prepared by JL and JD, and all authors contributed to the editing of the final manuscript.

\section{Acknowledgements}

The following research has been supported, in part, by Health Management Resources and the Atkins Foundation.

\section{References}

I. Kruger J, Blanck HM, Gillespie C: Dietary and physical activity behaviors among adults successful at weight loss maintenance. Int J Behav Nutr Phys Act 2006, 3:17.

2. Wing RR, Phelan S: Long-term weight loss maintenance. Am J Clin Nutr 2005, 82(I Suppl):222S-225S.

3. Brehm BJ, Seeley RJ, Daniels SR, D'Alessio DA: A randomized trial comparing a very low carbohydrate diet and a calorierestricted low fat diet on body weight and cardiovascular risk factors in healthy women. J Clin Endocrinol Metab 2003, 88(4): 1617-1623.

4. Foster GD, Wyatt HR, Hill JO, McGuckin BG, Brill C, Mohammed BS, Szapary PO, Rader DJ, Edman JS, Klein S: A randomized trial of a low-carbohydrate diet for obesity. N Engl J Med 2003, 348(2I):2082-2090.

5. Gardner CD, Kiazand A, Alhassan S, Kim S, Stafford RS, Balise RR, Kraemer HC, King AC: Comparison of the Atkins, Zone, Ornish, and LEARN diets for change in weight and related risk factors among overweight premenopausal women: the A TO Z Weight Loss Study: a randomized trial. Jama 2007, 297(9):969-977.

6. Samaha FF, Iqbai N, Seshadri P, Chicano KL, Daily DA, McGrory J, Williams T, Williams M, Gracely EJ, Stern L: A low-carbohydrate as compared with a low-fat diet in severe obesity. N EnglJ Med 2003, 348(2I):2074-208I.

7. Yancy WS Jr., Olsen MK, Guyton JR, Bakst RP, Westman EC: A lowcarbohydrate, ketogenic diet versus a low-fat diet to treat obesity and hyperlipidemia: a randomized, controlled trial. Ann Intern Med 2004, I 40( I 0):769-777.

8. Lin PH, Proschan MA, Bray GA, Fernandez CP, Hoben K, Most-Windhauser $M$, Karanja N, Obarzanek E: Estimation of energy requirements in a controlled feeding trial. Am J Clin Nutr 2003, 77(3):639-645.

9. Lohman TG: Research progress in validation of laboratory methods of assessing body composition. Med Sci Sports Exerc 1984, I 6(6):596-605.

10. Schuna AA: 1988 report of the Joint National Committee on Detection, Evaluation, and Treatment of High Blood Pressure: a commentary. Clin Pharm I988, 7(II):837-84I.

II. Chobanian AV, Bakris GL, Black HR, Cushman WC, Green LA, Izzo JL Jr., Jones DW, Materson BJ, Oparil S, Wright JT Jr., Roccella EJ: The Seventh Report of the Joint National Committee on Prevention, Detection, Evaluation, and Treatment of High Blood Pressure: the JNC 7 report. Jama 2003, 289(19):2560-2572

12. Brownell KD, Kramer FM: Behavioral management of obesity. Med Clin North Am 1989, 73(I): 185-20I.

13. Foreyt JP, Goodrick GK: Evidence for success of behavior modification in weight loss and control. Ann Intern Med 1993, I 19 (7 Pt 2):698-70I.

14. van Dale $\mathrm{D}$, Saris $\mathrm{WH}$, ten Hoor F: Weight maintenance and resting metabolic rate $18-40$ months after a diet/exercise treatment. Int J Obes 1990, 14(4):347-359.

15. Anderson JW, Konz EC, Frederich RC, Wood CL: Long-term weight-loss maintenance: a meta-analysis of US studies. Am J Clin Nutr 200I, 74(5):579-584.

16. Lantz H, Peltonen M, Agren L, Torgerson JS: A dietary and behavioural programme for the treatment of obesity. A 4-year clinical trial and a long-term posttreatment follow-up. J Intern Med 2003, 254(3):272-279.

17. Westerterp-Plantenga MS, Lejeune MP, Nijs I, van Ooijen M, Kovacs EM: High protein intake sustains weight maintenance after body weight loss in humans. Int J Obes Relat Metab Disord 2004, 28(I):57-64.
18. Kennedy AR, Pissios P, Otu HH, Xue B, Asakura K, Furukawa N, Marino FE, Liu FF, Kahn BB, Libermann TA, Maratos-Flier E: A High Fat, Ketogenic Diet, Induces a Unique Metabolic State in Mice. Am J Physiol Endocrinol Metab 2007.

19. Layman DK, Boileau RA, Erickson DJ, Painter JE, Shiue H, Sather C, Christou DD: A reduced ratio of dietary carbohydrate to protein improves body composition and blood lipid profiles during weight loss in adult women. J Nutr 2003, 133(2):41 I-4I7.

20. Nordmann AJ, Nordmann A, Briel M, Keller U, Yancy WS Jr., Brehm BJ, Bucher HC: Effects of low-carbohydrate vs low-fat diets on weight loss and cardiovascular risk factors: a meta-analysis of randomized controlled trials. Arch Intern Med 2006, I 66(3):285-293.

2I. McGuire MT, Wing RR, Klem ML, Lang W, Hill JO: What predicts weight regain in a group of successful weight losers? J Consult Clin Psychol 1999, 67(2): 177-185.

22. Shick SM, Wing RR, Klem ML, McGuire MT, Hill JO, Seagle H: Persons successful at long-term weight loss and maintenance continue to consume a low-energy, low-fat diet. J Am Diet Assoc 1998, 98(4):408-413.

23. Potteiger CE, Paragi PR, Inverso NA, Still C, Reed MJ, Strodel W 3rd, Rogers $M$, Petrick $A$ : Bariatric surgery: shedding the monetary weight of prescription costs in the managed care arena. Obes Surg 2004, 14(6):725-730.

24. Westman EC, Yancy WS, Edman JS, Tomlin KF, Perkins CE: Effect of 6-month adherence to a very low carbohydrate diet program. Am J Med 2002, II 3(I):30-36.

25. Weber JL, Reid PM, Greaves KA, DeLany JP, Stanford VA, Going SB, Howell WH, Houtkooper LB: Validity of self-reported energy intake in lean and obese young women, using two nutrient databases, compared with total energy expenditure assessed by doubly labeled water. Eur J Clin Nutr 200 I, 55(I I):940-950.
Publish with Biomed Central and every scientist can read your work free of charge

"BioMed Central will be the most significant development for disseminating the results of biomedical research in our lifetime. "

Sir Paul Nurse, Cancer Research UK

Your research papers will be:

- available free of charge to the entire biomedical community

- peer reviewed and published immediately upon acceptance

- cited in PubMed and archived on PubMed Central

- yours - you keep the copyright 